OPEN ACCESS

Edited by:

Hao Huang,

University of Pennsylvania, USA

Reviewed by:

Guy Elston,

Centre for Cognitive Neuroscience,

Australia

Mitsuru Kikuchi,

Kanazawa University, Japan

*Correspondence:

J. Christopher Edgar

edgarj@email.chop.edu

Received: 03 August 2015 Accepted: 22 September 2015

Published: 16 October 2015

Citation:

Edgar JC, Murray R, Kuschner ES, Pratt K, Paulson DN, Dell J, Golembski R, Lam P, Bloy L, Gaetz W and Roberts TPL (2015) The maturation of auditory responses in infants and young children: a cross-sectional study from 6 to 59 months.

Front. Neuroanat. 9:131. doi: 10.3389/fnana.2015.00131

\section{The maturation of auditory responses in infants and young children: a cross-sectional study from 6 to 59 months}

\author{
J. Christopher Edgar ${ }^{1 *}$, Rebecca Murray ${ }^{1}$, Emily S. Kuschner ${ }^{1}$, Kevin Pratt ${ }^{2}$, \\ Douglas N. Paulson ${ }^{2}$, John Dell ${ }^{1}$, Rachel Golembski ${ }^{1}$, Peter Lam ${ }^{1}$, Luke Bloy ${ }^{1}$, \\ William Gaetz ${ }^{1}$ and Timothy P. L. Roberts ${ }^{1}$ \\ 1 Lurie Family Foundations MEG Imaging Center, Department of Radiology, Children's Hospital of Philadelphia, Philadelphia, \\ PA, USA, ${ }^{2}$ Tristan Technologies, Inc., San Diego, CA, USA
}

Background: An understanding of the maturation of auditory cortex responses in typically developing infants and toddlers is needed to later identify auditory processing abnormalities in infants at risk for neurodevelopmental disorders. The availability of infant and young child magnetoencephalography (MEG) systems may now provide near optimal assessment of left and right hemisphere auditory neuromagnetic responses in young populations. To assess the performance of a novel whole-head infant MEG system, a cross-sectional study examined the maturation of left and right auditory cortex responses in children 6- to 59-months of age.

Methods: Blocks of $1000 \mathrm{~Hz}$ (1st and 3rd blocks) and $500 \mathrm{~Hz}$ tones (2nd block) were presented while MEG data were recorded using an infant/young child biomagnetometer (Artemis 123). Data were obtained from 29 children (11 males; 6- to 59-months). Latency measures were obtained for the first positive-to-negative evoked response waveform complex in each hemisphere. Latency and age associations as well as frequency and hemisphere latency differences were examined. For the $1000 \mathrm{~Hz}$ tone, measures of reliability were computed.

Results: For the first response-a response with a "P2m" topography-latencies decreased as a function of age. For the second response-a response with a "N2m" topography-no N2m latency and age relationships were observed. A main effect of tone frequency showed earlier P2m responses for 1st $1000 \mathrm{~Hz}$ (150 ms) and 2nd $1000 \mathrm{~Hz}$ (148 ms) vs. $500 \mathrm{~Hz}$ tones (162 ms). A significant main effect of hemisphere showed earlier $\mathrm{N} 2 \mathrm{~m}$ responses for 2nd $1000 \mathrm{~Hz}$ (226 ms) vs. 1st $1000 \mathrm{~Hz}$ (241 ms) vs. $500 \mathrm{~Hz}$ tones (265 ms). P2m and N2m interclass correlation coefficient latency findings were as follows: left P2m $(0.72, p<0.001)$, right P2m (0.84, $p<0.001)$, left N2m (0.77, $p<0.001)$, and right N2m (0.77, $p<0.01)$.

Conclusions: Findings of strong age and latency associations, sensitivity to tone frequency, and good test-retest reliability support the viability of longitudinal infant MEG 
studies that include younger as well as older participants as well as studies examining auditory processing abnormalities in infants at risk for neurodevelopmental disorders.

Keywords: infant, young child, magnetoencephalography, auditory

\section{INTRODUCTION}

Electroencephalography (EEG) studies have identified characteristic patterns of auditory long-latency responses in infants, with full-term neonates demonstrating a midline negativity that soon becomes a positive component (Kurtzberg et al., 1984). This midline positivity is sometimes referred to as the infantile P2 (Graziani et al., 1974; Barnet, 1975; Ohlrich et al., 1978; Rotteveel et al., 1987; Shucard et al., 1987). During development, a response of the opposite polarity is initially observed as a discontinuity in the P2 (Novak et al., 1989). Although there is nomenclature variability in the literature, with some groups referring to this opposite polarity response at about $200 \mathrm{~ms}$ as N1 (Barnet, 1975; Ohlrich et al., 1978; Novak et al., 1989) and others as N2 (Rotteveel et al., 1987; Shucard et al., 1987), the auditory event-related potential (ERP) is dominated by this positive-to-negative waveform morphology in infants and young children (Ceponiene et al., 2002; Kushnerenko et al., 2002).

Across infant and young child development there is rapid change in the latency of auditory responses. As an example, Barnet (1975) examined auditory responses (EEG electrode Cz) during sleep in 130 infants and children between the ages of 10 days and 37 months. Cross-sectional findings showed that over a 3-year period the latency decrease for P2 was approximately $75 \mathrm{~ms}$ and for N2 $215 \mathrm{~ms}$. A few longitudinal studies have studied also the maturation of auditory responses in infants and young children (Novak et al., 1989; Kushnerenko et al., 2002; Choudhury and Benasich, 2011). For example, Ohlrich et al. (1978) examined changes in auditory responses (EEG Cz) in 16 typically developing children tested repeatedly between the ages of 2 weeks and 3 years. Consistent with the crosssectional studies, significant changes in P2 and N2 latency were observed.

Although the majority of electrophysiological studies examining cortical auditory responses in infants and young children have used EEG, a few more recent studies have used adult magnetoencephalography (MEG) systems (Bosseler et al., 2013; Kuhl et al., 2014) and more recently, infant and young child whole-head MEG systems (Yoshimura et al., 2012; Roberts et al., 2014). For examining cortical auditory activity, MEG is sometimes preferred over EEG as the superior temporal gyrus (STG) auditory generators are favorably positioned to provide distinct measures of left and right STG activity given MEG's selective sensitivity to superficial tangentially-oriented neural currents and thus spatially-separated left and right auditory neuromagnetic fields (Edgar et al., 2003), even in infants and children (Paetau et al., 1995; Huotilainen et al., 2008). MEG is also sometimes preferred in studies examining neural brain activity in infants and young children as MEG is much less sensitive than EEG to distortions of the volume current caused by the incompletely developed fontanels and sutures in young populations and thus to inaccurate estimates of skull conductivity (Lew et al., 2013). Finally, MEG is also much less sensitive to conductivity differences between the brain to cerebral spinal fluid to skull to scalp, and thus for source localization MEG is sometimes preferred over EEG (Hämäläinen et al., 1993). Despite the difficulties examining auditory responses in infants using EEG, dense-array EEG and advanced source localization procedures (co-registering to age-appropriate MRI templates and using age-specific EEG conductivity measures) have been used to study the neural mechanisms associated with the acquisition of language in infants (Ortiz-Mantilla et al., 2012, 2013; Musacchia et al., 2013).

A limitation of conventional MEG is the fixed adult-sized sensor helmet, resulting in a substantial distance between brain neural generators and MEG detection coils in infants and young children, with this increased distance resulting in less-thanoptimal MEG recordings due to a loss of brain signal as a function of (the square of the) distance. To address this limitation, wholehead infant MEG system optimized for children have been developed (see reviews in Gaetz et al., 2015; Kikuchi et al., 2015). A few whole-head infant MEG studies have examined auditory neural responses in infants and young children (Yoshimura et al., 2012, 2013). For example, in a longitudinal infant MEG study, Yoshimura et al. (2014) measured auditory P1 $\mathrm{m}$ responses in twenty TD children at 36-75 months and then again 11-25 months later. A primary finding was that left hemisphere P51 $\mathrm{m}$ amplitude change was associated with positive change on a language conceptual inference task.

The present study used a recently developed whole-head MEG system-Artemis 123-with a helmet designed for the median 3 -year-old head circumference and thus ideal for studying infants and children given a decreased distance between neural brain activity and MEG detectors (Roberts et al., 2014). The present study reports on the sensitivity and reliability of the left and right auditory measures obtained using this novel MEG system, examining children aged 6- to 59-months. Based on prior findings, quality MEG auditory recordings would be demonstrated via the following findings: (1) the latency of the prominent positive-to-negative auditory response would decrease with age (left and right hemisphere auditory measures); (2) left and right auditory responses would be earlier to higher frequency $(1000 \mathrm{~Hz})$ vs. lower frequency tones $(500 \mathrm{~Hz})$, reflecting tonochronic principles (Roberts and Poeppel, 1996; Roberts et al., 1998, 2000); and (3) the latency of the response to the 1st and 3rd $1000 \mathrm{~Hz}$ tone blocks would be similar, indicating that the MEG obtained auditory measures are reliable. Positive findings would indicate that Artemis 123 provides quality primary/secondary auditory cortex recordings in infants and young children. 


\section{MATERIALS AND METHODS}

\section{Participants}

Participants were selected according to the following criteria: (1) between 6 and 60 months old; (2) speak/hear English as their first language; (3) no seizure disorder in the child or any immediate family members; (4) no premature birth; (5) no nonremovable metal in the body; (6) no known genetic conditions or neurological disorders; (7) no known hearing loss; and (8) no language or developmental delay concerns. Participants were included or excluded based on parental report via a phone screen. The study was approved by the Children's Hospital of Philadelphia IRB and all participants' families gave written consent.

Thirty-six children meeting study inclusion and exclusion criteria were enrolled. Of the enrolled children, MEG data were not obtained from four children because they were not able to place (or keep) their head in the MEG helmet: one 9-monthold male, one 10-month-old male, one 16-month-old female, and one 48-month-old male. MEG data were obtained but unusable from three children due to muscle artifact or technical problems: one 7-month-old female, one 10-month-old female, and one 12month-old male. Of the remaining 29 participants, a full dataset $(1000 \mathrm{~Hz}$ 1st, $500 \mathrm{~Hz}$ 1st, $1000 \mathrm{~Hz}$ 2nd) was obtained from 26 participants. A partial dataset $(1000 \mathrm{~Hz} 1 \mathrm{st}, 500 \mathrm{~Hz} \mathrm{1st,)}$ was obtained from the remaining three participants. In the final group of 29 participants, ages ranged from 6- to 59-months, with a mean age of 27.2 months $(S D=17.0)$. In the $6-11$ month age group there were four males and four females, in the 12 month to 23 month age group no males and five females, in the 24-35 month age group three males and four females, in the $36-47$ month age group one male and two females, and in the 48-59 month age group four males and two females.

\section{MEG Data Acquisition}

Whole-head MEG data were recorded using Artemis 123 (Tristan Technologies, San Diego, CA, USA) with a sampling rate of $5000 \mathrm{~Hz}$ and a $0.1-330 \mathrm{~Hz}$ bandpass. Stimuli consisted of 500 and $1000 \mathrm{~Hz}$ tones of $300 \mathrm{~ms}$ duration and $10 \mathrm{~ms}$ rise time. Stimuli were presented via a free field speaker at $80 \mathrm{~dB}$ SPL (Panphonics Sound Shower). Exams were blocked, presenting

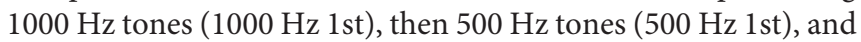
then a repeated block of $1000 \mathrm{~Hz}$ tones $(1000 \mathrm{~Hz} 2 \mathrm{nd})$. All tones were presented with a $2100 \mathrm{~ms}( \pm 500 \mathrm{~ms})$ inter-trial interval. As sleep can have an effect on the amplitude and latency of auditory responses (Weitzman et al., 1965; Barnet, 1975; Picton et al., 1981), recording were obtained only during an awake state. A variety of strategies were used to keep infants still and awake, including projecting a preferred video on the ceiling, toys to maintain their attention and focus (e.g., finger puppets, books, visually interesting sensory toys), and using a pacifier.

MEG data were analyzed using BESA 6.0 (BESA Gmbh). MEG data were downsampled to $300 \mathrm{~Hz}$. Epochs with large amplitude or gradient artifacts were manually rejected. The number of artifact-free trials per condition was: $1000 \mathrm{~Hz} 1$ st mean $=117($ range $53-206) ; 500 \mathrm{~Hz}$ mean $=119($ range $30-194)$, and $1000 \mathrm{~Hz}$ 2nd mean = 119 (range 82-158). Epochs $200 \mathrm{~ms}$ pre- to $400 \mathrm{~ms}$ post-stimulus were defined from the continuous recording, artifact-free epochs averaged according to stimulus type, and a $2-55 \mathrm{~Hz}$ bandpass filter applied. In almost all participants, an auditory response with a positive topography was observed at approximately $150 \mathrm{~ms}$, followed by a response with an opposite field pattern. Given similar findings from previous studies (see "Introduction" Section), the present study focused on this positive-to-negative evoked complex. Kushnerenko et al. (2002) noted that during early maturation an initial broad positivity in infants is divided into two positive peaks by the emergence of a growing negativity (N250), sometimes referred to as the P150 and the P350. In the present study, the first positivity preceding the N2 was measured. As in Barnet (1975), in the present study, these "positive" and "negative" responses are referred to as P2 and N2, although adding an " $\mathrm{m}$ " to obtain P2m and $\mathrm{N} 2 \mathrm{~m}$, as the recorded activity is magnetic rather than electric (for a similar approach, see also the language acquisition studies conducted by Rivera-Gaxiola et al. $(2005,2007,2012)$ examining the P150-250 and N250-550 in infants).

Given that continuous head position indicator (HPI) information was available only for the last few participants, the following procedure was used to obtain left and right $\mathrm{P} 2 \mathrm{~m}$ and N2m latency measures. First, after excluding all MEG sensors opposite the hemisphere of interest, $\mathrm{P} 2 \mathrm{~m}$ and $\mathrm{N} 2 \mathrm{~m}$ latencies were obtained from the 1 st component derived from a principal components analysis (PCA) applied to the sensor data. In all participants, field topography was examined to ensure that the $\mathrm{P} 2 \mathrm{~m}$ response and the $\mathrm{N} 2 \mathrm{~m}$ response had the characteristic magnetic field pattern. N2m was first identified, with P2m operationally defined as the first preceding response showing a reversed field pattern. Figure 1 shows example timecourse waveforms associated with the 1st PCA component for a subject in each age group.

\section{RESULTS}

\section{P2m and N2m Latency and Age Associations}

Correlations examined associations between P2m and $\mathrm{N} 2 \mathrm{~m}$ latency with age for each tone and hemisphere. As shown in Table 1, age and P2m latency associations were observed for all tones and in both hemispheres except right $500 \mathrm{~Hz}$, with a slope of $-0.6 \mathrm{~ms} / \mathrm{month}$ observed for most conditions. Age and $\mathrm{N} 2 \mathrm{~m}$ latency associations were not observed for any condition. The Figure 2 top row scatterplots compare age and latency associations for 500 and $1000 \mathrm{~Hz}$ 2nd tones. The Figure 2 bottom row scatterplots compare age and latency associations for the $1000 \mathrm{~Hz}$ 1st and $1000 \mathrm{~Hz}$ 2nd tones.

\section{P2m and N2m Latency}

Repeated measures ANOVA examined tone (1000 1st, 500 1st, and 1000 2nd) and hemisphere differences in P2m and N2m latency. Table 2 shows $\mathrm{P} 2 \mathrm{~m}$ and $\mathrm{N} 2 \mathrm{~m}$ mean and standard deviation latency values for each condition. For P2m, a main effect of tone, $F_{(2,18)}=7.18, p<0.01$, showed earlier $\mathrm{P} 2 \mathrm{~m}$ responses for 1st $1000 \mathrm{~Hz}(150 \mathrm{~ms})$ and $2 \mathrm{nd} 1000 \mathrm{~Hz}(148 \mathrm{~ms})$ 


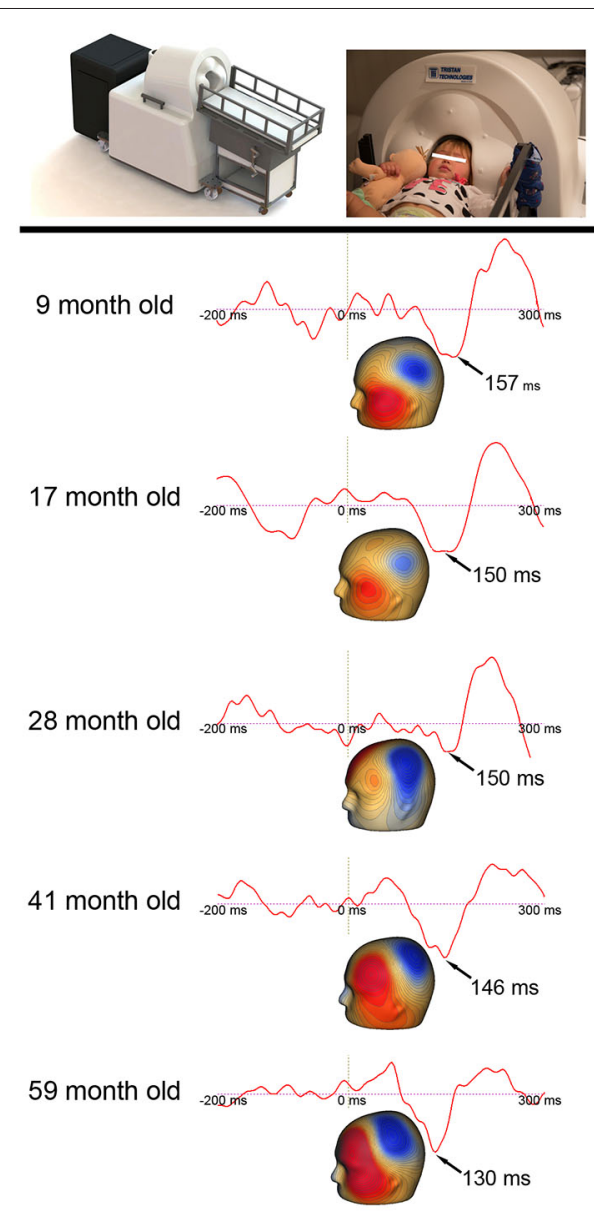

Left Hemisphere Auditory Responses

FIGURE 1 | The Artemis 123 system and a child placed in the helmet, along with left hemisphere auditory responses from five participants ranging in age from 6- to 59-months-old. The expected earlier P2m (magnetic field topography shown) auditory latencies in older ( 130 ms) vs. younger children $(\sim 157 \mathrm{~ms})$ is observed. Permission was granted by the family to publish the participant's photograph in the top panel.

vs. $500 \mathrm{~Hz}$ tones $(162 \mathrm{~ms})$. For N2m, a main effect of tone, $F_{(2,18)}=18.35, p<0.001$, showed earlier $\mathrm{N} 2 \mathrm{~m}$ responses for $2 \mathrm{nd}$ $1000 \mathrm{~Hz}(226 \mathrm{~ms})$ vs. $1 \mathrm{st} 1000 \mathrm{~Hz}(241 \mathrm{~ms})$ vs. $500 \mathrm{~Hz}$ tones (265 ms). No hemisphere or tone by hemisphere effects were observed for P2m or N2m ( $p$ 's $>0.19$ ).

\section{P2m and N2m Reliability}

To examine the similarity of the auditory measures, correlation analyses examined associations between $\mathrm{P} 2 \mathrm{~m}$ and $\mathrm{N} 2 \mathrm{~m}$ latencies to the $1000 \mathrm{~Hz}$ 1st and $1000 \mathrm{~Hz}$ 2nd tones. Left P2m latencies $(r=0.57, p<0.01)$ and right $\mathrm{P} 2 \mathrm{~m}$ latencies were significantly associated $(r=0.76, p<0.001)$. Left $\mathrm{N} 2 \mathrm{~m}$ latencies $(r=0.62$, $p<0.01)$ and right $\mathrm{N} 2 \mathrm{~m}$ latencies were also significantly associated $(r=0.71, p<0.001)$. Intraclass correlation coefficient (ICC) findings were as follows: left P2m $(0.72, p<0.001)$, right $\mathrm{P} 2 \mathrm{~m}(0.84, p<0.001)$, left N2m $(0.77, p<0.001)$, and right $\mathrm{N} 2 \mathrm{~m}$ (0.77, $p<0.01)$.
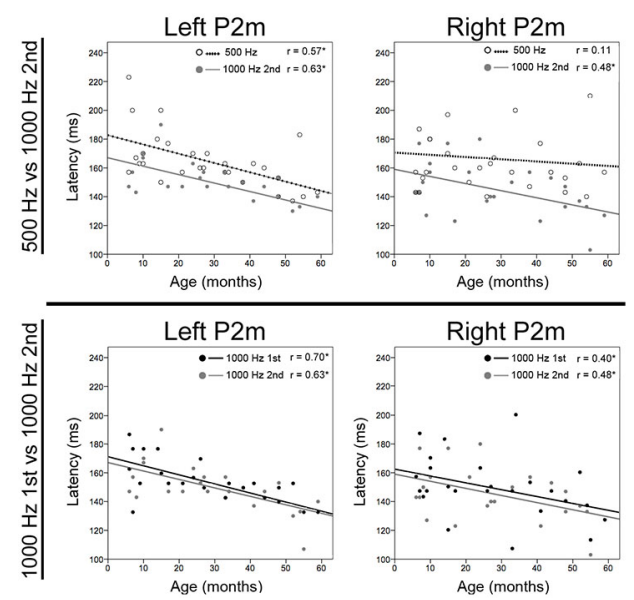

FIGURE 2 | Scatterplots showing associations for each tone between age and left and right P2m latency. The top row shows associations for $500 \mathrm{~Hz}$ (open circle and dotted line) and $1000 \mathrm{~Hz}$ 2nd tones (gray circle and line), and the bottom row shows associations for $1000 \mathrm{~Hz}$ 1st (black circle and line) and $1000 \mathrm{~Hz}$ 2nd tones. The $x$ axis shows age and the $y$ axis latency. Significant correlations are marked with an "*".

\section{DISCUSSION}

Strong cross-sectional $\mathrm{P} 2 \mathrm{~m}$ age and latency associations, robust findings of sensitivity to $500 \mathrm{~Hz}$ vs. $1000 \mathrm{~Hz}$ tone frequency, and good reliability measures (0.70-0.84), all support the viability of infant and young child Artemis 123 MEG auditory studies. Below, present findings are discussed within the context of previous findings.

Although direct comparisons to previous studies are difficult given that many earlier studies examined infants and children during sleep (Ohlrich et al., 1978), examined auditory responses at a single midline EEG electrode (Barnet, 1975; Ohlrich et al., 1978), or used an inter-stimulus interval shorter than that used in the present study Sharma et al. (2002), present findings were generally consistent with previous studies. For example, Ohlrich et al. (1978) reported a P2 latency of $153 \mathrm{~ms}$ in 3-year-old children, and Barnet (1975) a P2 latency between 150 and 170 in children between the ages of 1.5-3 years. Examining 4-yearold children, Ceponiene et al. (2002) observed a P1 latency of $114 \mathrm{~ms}$ and a N2 latency of $295 \mathrm{~ms}$ (midline EEG electrodes). Examining the auditory $\mathrm{Cz}$ response in 3-and 4-year-olds using a 2000 ms ISI, Gilley et al. (2005) reported a P2 latency of 145 ms. Using high-density EEG and assessing source localized left and right STG activity, Ortiz-Mantilla et al. (2013) observed in 6-month-olds a grand average left P1 latency of $176 \mathrm{~ms}$ and right P1 latency of $208 \mathrm{~ms}$ in response to consonant-vowel syllable stimuli and presenting stimuli at an approximately $700 \mathrm{~ms}$ ISI. Latencies in the present study, however, were somewhat longer than the P150 latencies of $139 \mathrm{~ms}$ in 9-month-olds and $142 \mathrm{~ms}$ in 12-month-olds reported in Kushnerenko et al. (2002), and the P1 latencies of $150 \mathrm{~ms}$ in 12-month-olds and $130 \mathrm{~ms}$ in 36month-olds reported in Choudhury and Benasich (2011), with study differences perhaps due to the use of a shorter ISI in these two studies vs. the present study. 
TABLE 1 | P2m and N2m latency associations with age.

\begin{tabular}{|c|c|c|c|c|c|c|}
\hline & \multicolumn{3}{|c|}{ P2m } & \multicolumn{3}{|c|}{ N2m } \\
\hline & $\begin{array}{c}\text { 1st } 1000 \mathrm{~Hz} \\
r \text {-value } \\
\text { and slope }\end{array}$ & $\begin{array}{c}500 \mathrm{~Hz} \\
r \text {-value } \\
\text { and slope }\end{array}$ & $\begin{array}{c}\text { 2nd } 1000 \mathrm{~Hz} \\
r \text {-value } \\
\text { and slope }\end{array}$ & $\begin{array}{c}\text { 1st } 1000 \mathrm{~Hz} \\
r \text {-value } \\
\text { and slope }\end{array}$ & $\begin{array}{c}500 \mathrm{~Hz} \\
r \text {-value } \\
\text { and slope }\end{array}$ & $\begin{array}{c}\text { 2nd } 1000 \mathrm{~Hz} \\
r \text {-value } \\
\text { and slope }\end{array}$ \\
\hline Left & $0.70^{* *}(-0.6 \mathrm{~ms} / \mathrm{month})$ & $0.57^{* *}$ (-0.6 ms/month) & $0.63^{* *}(-0.6 \mathrm{~ms} / \mathrm{month})$ & 0.11 (0.2 ms/month) & 0.11 (-0.2 ms/month) & 0.27 (-0.2 ms/month) \\
\hline Right & $0.40^{*}$ (-0.5 ms/month) & 0.11 (-0.2 ms/month) & $0.48^{*}(-0.5 \mathrm{~ms} / \mathrm{month})$ & 0.17 (0.3 ms/month) & 0.30 (0.6 ms/month) & 0.30 (-0.6 ms/month) \\
\hline
\end{tabular}

${ }^{*} p<0.05,{ }^{* *} p<0.01$.

In the present study, a latency decrease of $0.6 \mathrm{~ms} /$ month was observed for P2m (i.e., $7.2 \mathrm{~ms} /$ year), with $1000 \mathrm{~Hz}$ P2m latencies estimated to be approximately $170 \mathrm{~ms}$ at 6 months and $130 \mathrm{~ms}$ at 5 years. These rate-of-change estimates are again generally consistent with prior studies (Ohlrich et al., 1978; Novak et al., 1989). For example, in a longitudinal study following children from 6 months to 4 years, Choudhury and Benasich (2011) reported age-related decreases for the positive-going peaks of $20-80 \mathrm{~ms}$ over 4 years, and a decrease for the negative peaks of 9-50 ms over 4 years.

Infant and young child auditory responses differ from adult responses, and there is evidence that the $\mathrm{P} 2 \mathrm{~m}$ response examined in the present study eventually "becomes" the adult P50/M50 (P1) response (Kushnerenko et al., 2002; Ceponiene et al., 2003, 2008). The $1.9 \mathrm{~ms} /$ year rate-of change for P1 (EEG Fz) reported in Sharma et al. (1997) is slower than the rateof-change observed in the present sample, suggesting more rapid changes to $\mathrm{P} 2 \mathrm{~m}$ earlier in development, and then with slower although continued changes through childhood, and with adult-like STG P50/M50 latencies not observed until late adolescence.

The first negative component identified in infants is often labeled the N1, N250, or N2. The literature suggests that the $\mathrm{N} 2 \mathrm{~m}$ component does not develop into the adult M100 response. For example, in a longitudinal study (birth to 12 months), using harmonic tones, the infant N1 was identified at birth and showed consolidation by 6 months of age (Kushnerenko et al., 2002). The authors found that the infant $\mathrm{N} 1$ component did not change in latency from birth until 12 months of age, and they thus suggested that the infant N1 may be a correlate of the childhood N250. Similar findings have been reported in other studies (Pang and Taylor, 2000; Ponton et al., 2000). In the present study, the finding that $\mathrm{N} 2 \mathrm{~m}$ latency did not change as a function of age in children 6 months and older is consistent with previous studies (Onishi and Davis, 1969; Tanguay et al., 1973; Kushnerenko et al., 2002; Choudhury and Benasich, 2011), including observations from other studies showing that the adult N100/M100 is not robustly observed until early adolescence (Ponton et al., 2000, 2002; Edgar et al., 2014).

Previous studies have reported hemisphere differences in the maturation of left and right STG auditory cortex (Gomes et al., 2001). Although in older children and in adults earlier right than left M50 latencies are observed, in the present study, no $\mathrm{P} 2 \mathrm{~m}$ or $\mathrm{N} 2 \mathrm{~m}$ hemisphere latency differences were observed. Paetau et al. (1995) observed that in children 3-15 years auditory latencies tended to be earlier over the right than left hemisphere only in the older children. Examining EEG source localized left and right STG activity in 4-month-old infants, Musacchia et al. (2013) observed earlier right than left "P1" responses. The (Musacchia et al., 2013) inter-trial interval was much shorter than in the present study, perhaps suggesting that a right hemisphere auditory encoding advantage may be observed only under more demanding encoding conditions. Longitudinal studies following children from infancy through early adolescence are needed to better understand the development of infant and young child $\mathrm{P} 2 \mathrm{~m}$ responses and transition to adult M50 responses.

Changes to the auditory response (morphology and latency) as a function of age are hypothesized to be due to maturation of gray and white matter structure, such as age-related changes in synaptic efficiency (Goodin et al., 1978; Eggermont, 1988), cortical layer maturational changes (Steinschneider et al., 1994; Eggermont and Ponton, 2003). Maturational changes to the morphology of primary auditory cortex pyramidal cells are also observed (Elston et al., 2010; Elston and Fujita, 2014), with such changes of interest as MEG recordings primarily reflect pyramidal cell activity (Lewine and Orrison, 1995; Spruston, 2008). Multimodal human in vivo imaging studies are beginning to demonstrate how brain structure is related to brain function. For example, multimodal MEG and diffusion MR children and adolescent studies have shown that the latency

TABLE 2 | P2m and N2m latency.

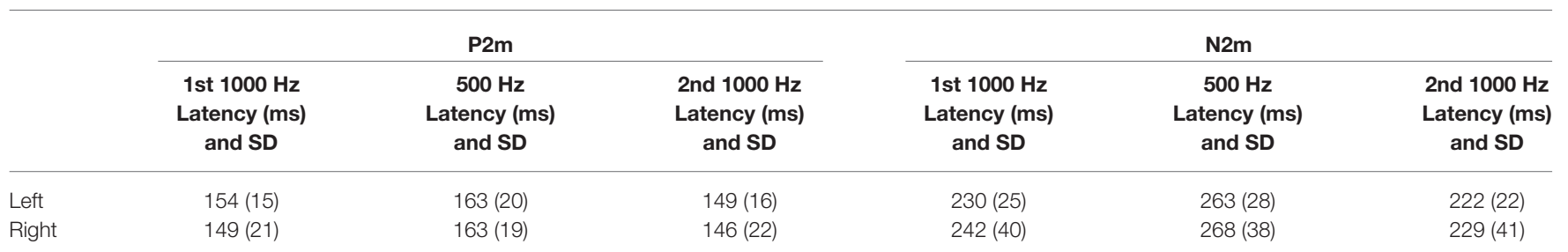


of auditory responses decreases as a function of maturation of local white matter myelination (Roberts et al., 2009, 2013). In adults, studies have noted associations between gray matter cortical thickness and the strength of auditory responses (Edgar et al., 2012). Studies examining auditory cortex function and structure associations in infants and young children are now needed.

A few limitations of the present study are of note. First, given that HPI coil information was not available from most of the participants, it was not possible to determine the exact location of the infant or child's head in the helmet and thus not possible to accurately estimate the strength of auditory responses. As such, although age-related auditory component amplitude changes are of interest in infants and young children (Ponton et al., 2002; Gilley et al., 2005; Yoshimura et al., 2014), examination of amplitude and age associations was not possible in the present study. Second, auditory responses in infants and children likely depend on the type of stimuli such as speech or non-speech stimuli (Friedman et al., 1984; Kurtzberg et al., 1984;

\section{REFERENCES}

Barnet, A. B. (1975). Auditory evoked potentials during sleep in normal children from ten days to three years of age. Electroencephalogr. Clin. Neurophysiol. 39, 29-41. doi: 10.1016/0013-4694(75)90124-8

Bosseler, A. N., Taulu, S., Pihko, E., Mäkelä, J. P., Imada, T., Ahonen, A., et al. (2013). Theta brain rhythms index perceptual narrowing in infant speech perception. Front. Psychol. 4:690. doi: 10.3389/fpsyg.2013.00690

Ceponiene, R., Lepisto, T., Alku, P., Aro, H., and Naatanen, R. (2003). Eventrelated potential indices of auditory vowel processing in 3-year-old children. Clin. Neurophysiol. 114, 652-661. doi: 10.1016/s1388-2457(02)00436-4

Ceponiene, R., Rinne, T., and Näätänen, R. (2002). Maturation of cortical sound processing as indexed by event-related potentials. Clin. Neurophysiol. 113, 870-882. doi: 10.1016/s1388-2457(02)00078-0

Ceponiene, R., Torki, M., Alku, P., Koyama, A., and Townsend, J. (2008). Eventrelated potentials reflect spectral differences in speech and non-speech stimuli in children and adults. Clin. Neurophysiol. 119, 1560-1577. doi: 10.1016/j. clinph.2008.03.005

Choudhury, N., and Benasich, A. A. (2011). Maturation of auditory evoked potentials from 6 to 48 months: prediction to 3 and 4 year language and cognitive abilities. Clin. Neurophysiol. 122, 320-338. doi: 10.1016/j.clinph.2010. 05.035

Edgar, J. C., Huang, M. X., Weisend, M. P., Sherwood, A., Miller, G. A., Adler, L. E., et al. (2003). Interpreting abnormality: an EEG and MEG study of P50 and the auditory paired-stimulus paradigm. Biol. Psychol. 65, 1-20. doi: 10.1016/s03010511(03)00094-2

Edgar, J. C., Hunter, M. A., Huang, M., Smith, A. K., Chen, Y., Sadek, J., et al. (2012). Temporal and frontal cortical thickness associations with M100 auditory activity and attention in healthy controls and individuals with schizophrenia. Schizophr. Res. 140, 250-257. doi: 10.1016/j.schres.2012. 06.009

Edgar, J. C., Lanza, M. R., Daina, A. B., Monroe, J. F., Khan, S. Y., Blaskey, L., et al. (2014). Missing and delayed auditory responses in young and older children with autism spectrum disorders. Front. Hum. Neurosci. 8:417. doi: 10. 3389/fnhum.2014.00417

Eggermont, J. J. (1988). On the rate of maturation of sensory evoked potentials. Electroencephalogr. Clin. Neurophysiol. 70, 293-305. doi: 10.1016/00134694(88)90048-x

Eggermont, J. J., and Ponton, C. W. (2003). Auditory-evoked potential studies of cortical maturation in normal hearing and implanted children: correlations with changes in structure and speech perception. Acta Otolaryngol. 123, 249-252. doi: 10.1080/0036554021000028098
Pang and Taylor, 2000), with present findings thus limited in their generality. Finally, a limitation of the present study is that acquisitions, and thus analyses, were cross-sectional rather than longitudinal.

\section{CONCLUSION}

Strong cross-sectional P2m age and latency associations, robust findings of sensitivity to tone frequency, and good reliability measures all support the viability of infant and young child Artemis 123 MEG auditory studies.

\section{FUNDING}

This research was supported by grants from the Nancy Lurie Marks Family Foundation, a IDDRC grant to CHOP (U54 HD08694), and the Pennsylvania Department of Health. The Pennsylvania Department of Health specifically disclaims responsibility for any analyses, interpretations or conclusions.

Elston, G. N., and Fujita, I. (2014). Pyramidal cell development: postnatal spinogenesis, dendritic growth, axon growth and electrophysiology. Front. Neuroanat. 8:78. doi: 10.3389/fnana.2014.00078

Elston, G. N., Okamoto, T., Oga, T., Dornan, D., and Fujita, I. (2010). Spinogenesis and pruning in the primary auditory cortex of the macaque monkey (Macaca fascicularis): an intracellular injection study of layer III pyramidal cells. Brain Res. 1316, 35-42. doi: 10.1016/j.brainres.2009.12.056

Friedman, D., Brown, C., Vaughan, H. G. Jr., Cornblatt, B., and Erlenmeyer-Kimling, L. (1984). Cognitive brain potential components in adolescents. Psychophysiology 21, 83-96. doi: 10.1111/j.1469-8986.1984. tb02322.x

Gaetz, W., Gordon, R. S., Papadelis, C., Fujiwara, H., Rose, D. F., Edgar, J. C., et al. (2015). Magnetoencephalography for clinical pediatrics: recent advances in hardware, methods and clinical applications. J. Pediatr. Epilepsy 4, (in press). doi: 10.1055/s-0035-1563726

Gilley, P. M., Sharma, A., Dorman, M., and Martin, K. (2005). Developmental changes in refractoriness of the cortical auditory evoked potential. Clin. Neurophysiol. 116, 648-657. doi: 10.1016/j.clinph. 2004.09.009

Gomes, H., Dunn, M., Ritter, W., Kurtzberg, D., Brattson, A., Kreuzer, J. A., et al. (2001). Spatiotemporal maturation of the central and lateral N1 components to tones. Brain Res. Dev. Brain Res. 129, 147-155. doi: 10.1016/s0165 3806(01)00196-1

Goodin, D. S., Squires, K. C., Henderson, B. H., and Starr, A. (1978). Age-related variations in evoked potentials to auditory stimuli in normal human subjects. Electroencephalogr. Clin. Neurophysiol. 44, 447-458. doi: 10. 1016/0013-4694(78)90029-9

Graziani, L. J., Katz, L., Cracco, Q., Cracco, J. B., and Weitzman, E. D. (1974). The maturation and interrelationship of EEF patterns and auditory evoked response in premature infants. Electroencephalogr. Clin. Neurophysiol. 36, 367-375. doi: 10.1016/0013-4694(74)90186-2

Hämäläinen, M., Hari, R., Ilmoniemi, R. J., Knuutila, J., and Lounasmaa, O. V. (1993). Magnetoencephalograph-theory, instrumentation and applications to noninvasive studies of the working human brain. Rev. Mod. Phys. 65, 413-497. doi: 10.1103/revmodphys.65.413

Huotilainen, M., Shestakova, A., and Hukki, J. (2008). Using magnetoencephalography in assessing auditory skills in infants and children. Int. J. Psychophysiol. 68, 123-129. doi: 10.1016/j.ijpsycho.2007.12.007

Kikuchi, M., Yoshimura, Y., Mutou, K., and Minabe, Y. (2015). Magnetoencephalography in the study of children with autism spectrum disorder. Psychiatry Clin. Neurosci. doi: 10.1111/pcn.12338 [Epub ahead of print]. 
Kuhl, P. K., Ramírez, R. R., Bosseler, A., Lin, J. F., and Imada, T. (2014). Infants' brain responses to speech suggest analysis by synthesis. Proc. Natl. Acad. Sci. U S A 111, 11238-11245. doi: 10.1073/pnas.14109 63111

Kurtzberg, D., Hilpert, P. L., Kreuzer, J. A., Vaughan, H. G. Jr. (1984). Differential maturation of cortical auditory evoked potentials to speech sounds in normal fullterm and very low-birthweight infants. Dev. Med. Child Neurol. 26, 466-475. doi: 10.1111/j.1469-8749.1984.tb04473.x

Kushnerenko, E., Ceponiene, R., Balan, P., Fellman, V., Huotilaine, M., and Näätäne, R. (2002). Maturation of the auditory event-related potentials during the first year of life. Neuroreport 13, 47-51. doi: 10.1097/00001756-20020121000014

Lew, S., Sliva, D. D., Choe, M. S., Grant, P. E., Okada, Y., Wolters, C. H., et al. (2013). Effects of sutures and fontanels on MEG and EEG source analysis in a realistic infant head model. Neuroimage 76, 282-293. doi: 10.1016/j. neuroimage.2013.03.017

Lewine, J. D., and Orrison, W. W. (1995). "Magnetencephalography and magnetic source imaging," in Functional Brain Imaging, eds W. W. L. J. Orrison, J. A. Sanders, and M. F. Hartshorne (St. Louis: Mosby), 369-417.

Musacchia, G., Choudhury, N. A., Ortiz-Mantilla, S., Realpe-Bonilla, T., Roesler, C. P., and Benasich, A. A. (2013). Oscillatory support for rapid frequency change processing in infants. Neuropsychologia 51, 2812-2824. doi: 10.1016/j. neuropsychologia.2013.09.006

Novak, G. P., Kurtzberg, D., Kreuzer, J. A., and Vaughan, H. G. Jr. (1989). Cortical responses to speech sounds and their formants in normal infants: maturational sequence and spatiotemporal analysis. Electroencephalogr. Clin. Neurophysiol. 73, 295-305. doi: 10.1016/0013-4694(89) 90108-9

Ohlrich, E. S., Barnet, A. B., Weiss, I. P., and Shanks, B. L. (1978). Auditory evoked potential development in early childhood: a longitudinal study. Electroencephalogr. Clin. Neurophysiol. 44, 411-423. doi: 10.1016/00134694(78)90026-3

Onishi, S., and Davis, H. (1969). Auditory evoked responses in the sleeping infant. Electroencephalogr. Clin. Neurophysiol. 26:114.

Ortiz-Mantilla, S., Hämäläinen, J. A., and Benasich, A. A. (2012). Time course of ERP generators to syllables in infants: a source localization study using age-appropriate brain templates. Neuroimage 59, 3275-3287. doi: 10.1016/j. neuroimage.2011.11.048

Ortiz-Mantilla, S., Hämäläinen, J. A., Musacchia, G., and Benasich, A. A. (2013). Enhancement of gamma oscillations indicates preferential processing of native over foreign phonemic contrasts in infants. J. Neurosci. 33, 18746-18754. doi: 10.1523/jneurosci.3260-13.2013

Paetau, R., Ahonen, A., Salonen, O., and Sams, M. (1995). Auditory evoked magnetic fields to tones and pseudowords in healthy children and adults. J. Clin. Neurophysiol. 12, 177-185. doi: 10.1097/00004691-19950300000008

Pang, E. W., and Taylor, M. J. (2000). Tracking the development of the N1 from age 3 to adulthood: an examination of speech and nonspeech stimuli. Clin. Neurophysiol. 111, 388-397. doi: 10.1016/s1388-2457(99) 00259-x

Picton, T. W., Stapells, D. R., and Campbell, K. B. (1981). Auditory evoked potentials from the human cochlea and brainstem. J. Otolaryngol. Suppl. 9, $1-41$.

Ponton, C., Eggermont, J. J., Khosla, D., Kwong, B., and Don, M. (2002). Maturation of human central auditory system activity: separating auditory evoked potentials by dipole source modeling. Clin. Neurophysiol. 113, 407-420. doi: 10.1016/s1388-2457(01)00733-7

Ponton, C. W., Eggermont, J. J., Kwong, B., and Don, M. (2000). Maturation of human central auditory system activity: evidence from multi-channel evoked potentials. Clin. Neurophysiol. 111, 220-236. doi: 10.1016/s13882457(99)00236-9

Rivera-Gaxiola, M., Garcia-Sierra, A., Lara-Ayala, L., Cadena, C., JacksonMaldonado, D., and Kuhl, P. (2012). Event-related potentials to an english/spanish syllabic contrast in mexican 10-13-month-old infants. ISRN Neurol. 2012:702986. doi: 10.5402/2012/702986

Rivera-Gaxiola, M., Silva-Pereyra, J., Klarman, L., Garcia-Sierra, A., Lara-Ayala, L., Cadena-Salazar, C., et al. (2007). Principal component analyses and scalp distribution of the auditory P150-250 and N250-550 to speech contrasts in Mexican and American infants. Dev. Neuropsychol. 31, 363-378. doi: 10 $1080 / 87565640701229292$

Rivera-Gaxiola, M., Silva-Pereyra, J., and Kuhl, P. K. (2005). Brain potentials to native and non-native speech contrasts in 7 - and 11-month-old American infants. Dev. Sci. 8, 162-172. doi: 10.1111/j.1467-7687.2005. 00403.x

Roberts, T. P., Ferrari, P., and Poeppel, D. (1998). Latency of evoked neuromagnetic M100 reflects perceptual and acoustic stimulus attributes. Neuroreport 9, 3265-3269. doi: 10.1097/00001756-19981005000024

Roberts, T. P., Ferrari, P., Stufflebeam, S. M., and Poeppel, D. (2000). Latency of the auditory evoked neuromagnetic field components: stimulus dependence and insights toward perception. J. Clin. Neurophysiol. 17, 114-129. doi: 10. 1097/00004691-200003000-00002

Roberts, T. P., Khan, S. Y., Blaskey, L., Dell, J., Levy, S. E., Zarnow, D. M., et al. (2009). Developmental correlation of diffusion anisotropy with auditory-evoked response. Neuroreport 20, 1586-1591. doi: 10.1097/wnr. ob013e3283306854

Roberts, T. P., Lanza, M. R., Dell, J., Smieh, S., Hines, K., Blaskey, L., et al. (2013). Maturational differences in thalamocortical white matter microstructure and auditory evoked response latencies in autism spectrum disorders. Brain Res. 1537, 79-85. doi: 10.1016/j.brainres.2013. 09.011

Roberts, T. P., Paulson, D. N., Hirschkoff, E., Pratt, K., Mascarenas, A., Miller, P., et al. (2014). Artemis 123: development of a whole-head infant and young child MEG system. Front. Hum. Neurosci. 8:99. doi: 10.3389/fnhum.2014. 00099

Roberts, T. P., and Poeppel, D. (1996). Latency of auditory evoked M100 as a function of tone frequency. Neuroreport 7, 1138-1140. doi: 10.1097/00001756199604260-00007

Rotteveel, J. J., de Graaf, R., Stegeman, D. F., Colon, E. J., and Visco, Y. M. (1987). The maturation of the central auditory conduction in preterm infants until three months post term. V. The auditory cortical response (ACR). Hear. Res. 27, 95-110. doi: 10.1016/0378-5955(87) 90029-3

Sharma, A., Dorman, M. F., and Spahr, A. J. (2002). A sensitive period for the development of the central auditory system in children with cochlear implants: implications for age of implantation. Ear Hear. 23, 532-539. doi: 10. 1097/00003446-200212000-00004

Sharma, A., Kraus, N., McGee, T. J., and Nicol, T. G. (1997). Developmental changes in $\mathrm{P} 1$ and $\mathrm{N} 1$ central auditory responses elicited by consonantvowel syllables. Electroencephalogr. Clin. Neurophysiol. 104, 540-545. doi: 10. 1016/s0168-5597(97)00050-6

Shucard, D. W., Shucard, J. L., and Thomas, D. G. (1987). Auditory eventrelated potentials in waking infants and adults: a developmental perspective. Electroencephalogr. Clin. Neurophysiol. 68, 303-310. doi: 10.1016/01685597(87)90051-7

Spruston, N. (2008). Pyramidal neurons: dendritic structure and synaptic integration. Nat. Rev. Neurosci. 9, 206-221. doi: 10.1038/ nrn2286

Steinschneider, M., Schroeder, C. E., Arezzo, J. C., and Vaughan, H. G. Jr. (1994). Speech-evoked activity in primary auditory cortex: effects of voice onset time. Electroencephalogr. Clin. Neurophysiol. 92, 30-43. doi: 10.1016/01685597(94)90005-1

Tanguay, P. E., Lee, J. C., and Ornitz, E. M. (1973). A detailed analysis of the auditory evoked response wave form in children during REM and stage 2 sleep. Electroencephalogr. Clin. Neurophysiol. 35, 241-248. doi: 10.1016/00134694(73)90235-6

Weitzman, E. D., Fishbein, W., and Graziani, L. (1965). Auditory evoked responses obtained from the scalp electroencephalogram of the full-term human neonate during sleep. Pediatrics 35, 458-462.

Yoshimura, Y., Kikuchi, M., Shitamichi, K., Ueno, S., Munesue, T., Ono, Y., et al. (2013). Atypical brain lateralisation in the auditory cortex and language performance in 3- to 7-year-old children with high-functioning autism spectrum disorder: a child-customised magnetoencephalography (MEG) study. Mol. Autism 4:38. doi: 10.1186/2040-2392-4-38

Yoshimura, Y., Kikuchi, M., Shitamichi, K., Ueno, S., Remijn, G. B., Haruta, Y., et al. (2012). Language performance and auditory evoked fields in 2- to 
5-year-old children. Eur. J. Neurosci. 35, 644-650. doi: 10.1111/j.1460-9568. 2012.07998.x

Yoshimura, Y., Kikuchi, M., Ueno, S., Shitamichi, K., Remijn, G. B., Hiraishi, H., et al. (2014). A longitudinal study of auditory evoked field and language development in young children. Neuroimage 101, 440-447. doi: 10.1016/j. neuroimage.2014.07.034

Conflict of Interest Statement: The Associate Editor Dr. Huang declares that, despite being affiliated to the same university as the authors, the review process was handled objectively. The authors declare that the research was conducted in the absence of any commercial or financial relationships that could be construed as a potential conflict of interest.

Copyright (๑) 2015 Edgar, Murray, Kuschner, Pratt, Paulson, Dell, Golembski, Lam, Bloy, Gaetz and Roberts. This is an open-access article distributed under the terms of the Creative Commons Attribution License (CC BY). The use, distribution and reproduction in other forums is permitted, provided the original author(s) or licensor are credited and that the original publication in this journal is cited, in accordance with accepted academic practice. No use, distribution or reproduction is permitted which does not comply with these terms. 